Article

\title{
A Novel Niosome-Encapsulated Essential Oil Formulation to Prevent Aspergillus flavus Growth and Aflatoxin Contamination of Maize Grains During Storage
}

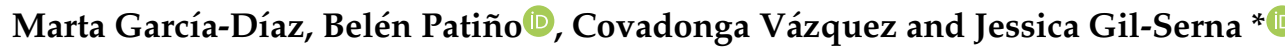 \\ Department of Genetics, Physiology and Microbiology, Faculty of Biology, University Complutense of Madrid, \\ Jose Antonio Novais 12, 28040 Madrid, Spain; martga43@ucm.es (M.G.-D.); belenp@ucm.es (B.P.); \\ covi@ucm.es (C.V.) \\ * Correspondence: jgilsern@ucm.es
}

Received: 18 October 2019; Accepted: 5 November 2019; Published: 6 November 2019

check for updates

\begin{abstract}
Aflatoxin (AF) contamination of maize is a major concern for food safety. The use of chemical fungicides is controversial, and it is necessary to develop new effective methods to control Aspergillus flavus growth and, therefore, to avoid the presence of AFs in grains. In this work, we tested in vitro the effect of six essential oils (EOs) extracted from aromatic plants. We selected those from Satureja montana and Origanum virens because they show high levels of antifungal and antitoxigenic activity at low concentrations against $A$. flavus. EOs are highly volatile compounds and we have developed a new niosome-based encapsulation method to extend their shelf life and activity. These new formulations have been successfully applied to reduce fungal growth and AF accumulation in maize grains in a small-scale test, as well as placing the maize into polypropylene woven bags to simulate common storage conditions. In this latter case, the antifungal properties lasted up to 75 days after the first application.
\end{abstract}

Keywords: essential oils; Satureja montana; Origanum virens; Aspergillus flavus; aflatoxin; corn; nanoparticles

Key Contribution: A safe, ecofriendly, novel strategy was developed to prevent aflatoxin contamination of maize during storage. This method uses niosome-encapsulated EOs extracted from Satureja montana and Origanum virens and is able to control Aspergillus flavus growth for long periods.

\section{Introduction}

Aflatoxins (AFs) are secondary metabolites produced primarily by Aspergillus flavus and Aspergillus parasiticus. Aflatoxin $\mathrm{B}_{1}, \mathrm{~B}_{2}, \mathrm{G}_{1}$, and $\mathrm{G}_{2}\left(\mathrm{AFB}_{1}, \mathrm{AFB}_{2}, \mathrm{AFG}_{1}\right.$, and $\left.\mathrm{AFG}_{2}\right)$ are the most important ones, with $\mathrm{AFB}_{1}$ being the most toxic naturally occurring human carcinogen [1,2]. The International Agency for Research on Cancer (IARC) has classified the "naturally occurring mixes of aflatoxins" as Group 1 carcinogens in humans [3].

AFs contaminate a variety of staple crops including cereals (maize, sorghum, barley, oat, rye, rice, and wheat), soya, dry nuts (nuts, pistachios, almonds, and hazelnuts), cottonseed, coffee, cacao, and spices [4].

According to the Food and Agriculture Organization of the United Nations (FAO) [5], maize is one of the most important cereals, with an annual worldwide production of 1134 million tons in 2017, and most of it is intended for direct human and animal consumption. Moreover, maize and its derivatives are considered the main source of AFs worldwide [6]. For all these reasons, the European Union established strict regulations regarding maximum permitted AF levels for maize [7]. 
The impact of AF contamination of agri-food products is significant. It causes important economic losses because infected products cannot be sold and the contamination also raises veterinary and health costs. Establishing adequate controls to avoid AFs in the food chain is thus essential [8].

Different strategies to prevent $\mathrm{AF}$ contamination have been proposed to reduce fungal development in the field or during storage. Applying good agricultural practices and maintaining adequate humidity and temperature in silos are indispensable in reducing fungal growth and, therefore, mycotoxin contamination [9]. Chemical compounds are useful in preventing fungal growth and, for a long time, have been widely used both in the field and during storage to prevent mycotoxin contamination [10]. However, synthetic fungicides are in the spotlight and consumers are now demanding safer foodstuffs that are produced using sustainable and ecofriendly methods. The indiscriminate use of chemical fungicides has important drawbacks, including residue on grain that threatens human and animal health or causes extensive environmental contamination [11]. Moreover, the indiscriminate use of fungicides has caused an increased number of resistant isolates, which makes it very difficult to effectively control fungal growth [12].

The risks of using synthetic chemicals have increased public awareness and demand for safer and ecofriendly products and, in this context, natural plant extracts are now considered good alternatives. Essential oils (EOs) extracted from aromatic plants have demonstrated strong antibacterial, antifungal, and food preservative properties, together with low toxicity, fewer environmental effects, and wider public acceptance [13]. Many EO-based formulations are listed on the generally recognized as safe (GRAS) list, fully approved by the Food and Drug Administration, and are currently commercially available as food preservatives and/or agricultural supplements [14]. Several EOs have been reported to not only reduce growth in toxigenic fungal species, but also to interfere to some extent in mycotoxin biosynthesis. Da Silva et al. [15] reported that Rosmarinus officinalis EO has a strong effect against Fusarium verticillioides, as it showed the ability to rupture the cell wall and inhibit the production of fumonisins. Aspergillus flavus growth and its ability to produce AFs were also significantly affected by treatment with Origanum virens and Ageratum conyzoides EOs in corn and soybeans [16], and using Mentha spicata EO in chickpeas [17].

Therefore, the use of EOs to prevent fungal growth during maize storage could be a sustainable solution to minimize food losses owing to mycotoxin contamination. However, their direct application in food products seems to be limited because of their high volatility, low water solubility, and susceptibility to oxidation [18]. To solve these problems, various encapsulation techniques have been developed that can preserve EOs through a physical or chemical interaction with a matrix that maintains the compounds for a longer time [19]. Encapsulation of EOs also increases stability against oxidation, which helps to prolong their antimicrobial activity $[18,20]$. Different methods of encapsulation have also been demonstrated to enhance the antifungal and antiaflatoxigenic properties when applied to control A. flavus [21].

These encapsulation particles form a protective film that isolates the nucleus that contains the active agent. The composition of the particles should be carefully chosen depending on the encapsulated compound. To date, several natural and synthetic matrices have been successfully used to encapsulate EOs including polyethylene, carbohydrates, proteins, lipids, and gum [22]. The choice of the encapsulation material is a crucial step in developing an appropriate application method for EOs. Different parameters should be taken into account such as the polarity, solubility, and volatility of the active compounds, as well as the composition of the food matrix [23]. Niosomes are lipid-based systems, composed by non-toxic self-assembly vesicles, with a single or multiple layered structure, which are able to encapsulate hydrophobic and hydrophilic compounds [24]. Niosomes are biodegradable, easily stored and handled, and present low toxicity, which are important advantages for their application in the food industry [24].

The aim of this work was to evaluate the in vitro antifungal and antitoxigenic effects of different aromatic plant EOs and to design an effective niosome-based encapsulation protocol to avoid AF contamination during maize storage. 


\section{Results}

\subsection{The Efficacy of Plant Essential Oils Against Fungal Growth and Mycotoxin Production}

Figures 1 and 2 show the results for the Aspergillus flavus growth rate ( $\mu, \mathrm{mm} / \mathrm{day})$ and the lag phase prior to growth $(\lambda, h)$, respectively, in CYA (Czapek Yeast Autolysate Agar) plates supplemented with different essential oils (EOs) (Rosmarinus officinalis, Thymus vulgaris, Satureja montana, Origanum virens, O. majoricum, and O. vulgare) at several different concentrations $(0,10,100,500$, and $1000 \mu \mathrm{g} / \mathrm{mL})$.

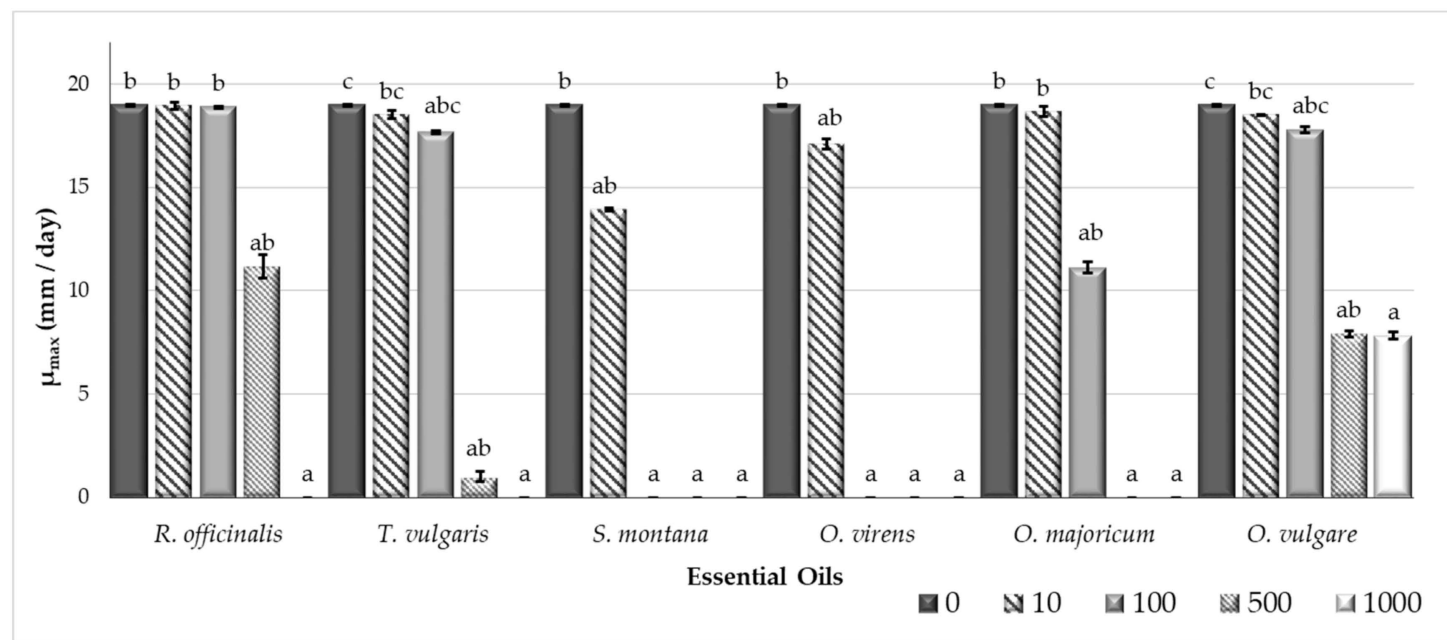

Figure 1. Aspergillus flavus S.44-1 growth rate (mm/day) at different concentrations (0, 10, 100, 500, and $1000 \mu \mathrm{g} / \mathrm{mL}$ ) of essential oils (R. officinalis, T. vulgaris, S. montana, O. virens, O. majoricum, and O. vulgare). Each value is the mean of three replications and the thin vertical bars represent the standard error of the corresponding data. Groups with the same letter are not significantly different $(p>0.05)$.

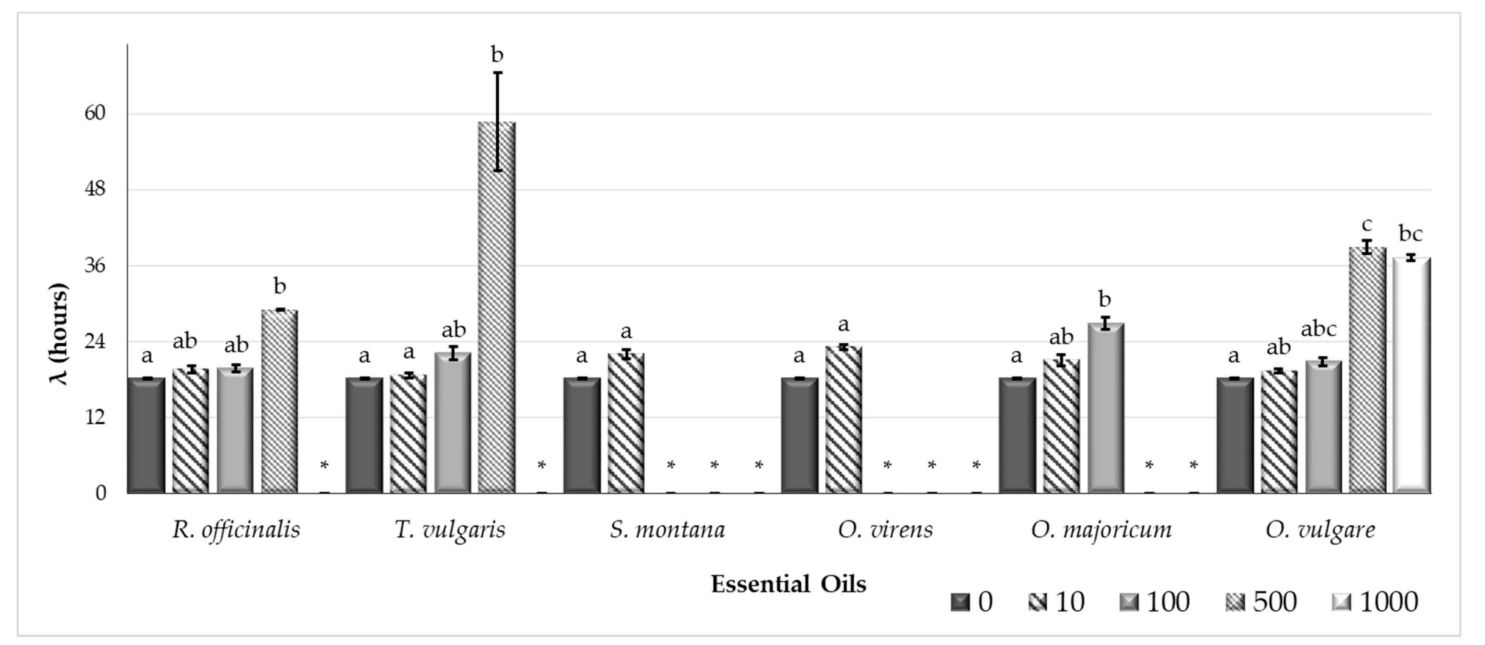

Figure 2. Aspergillus flavus S.44-1 lag phase (h) at different concentrations (0, 10, 100, 500, and 1,000 $\mu \mathrm{g} / \mathrm{mL}$ ) of essential oils (R. officinalis, T. vulgaris, S. montana, O. virens, O. majoricum, and O. vulgare). Each value is the mean of three replications and the thin vertical bars represent the standard error of the corresponding data. Groups with the same letter are not significantly different $(p>0.05)$. ${ }^{*}$ No data.

All EOs tested had a significant effect on the A. flavus growth rate at the maximum concentration (Figure 1). Fungal growth was completely inhibited, except for the O. vulgare EO. For the EOs of O. virens and S. montana, total inhibition was reached at $100 \mu \mathrm{g} / \mathrm{mL}$. Thymus vulgaris and O. majoricum EOs also showed reductions of at least $95 \%$ at $500 \mu \mathrm{g} / \mathrm{mL}$. 
The lag phase got longer as the EO concentration increased (Figure 2). It was not possible to calculate the lag phase when the EO treatment completely inhibited growth in the plates.

Aflatoxin production $\left(\mathrm{AFB}_{1}, \mathrm{AFB}_{2}, \mathrm{AFG}_{1} \mathrm{y} \mathrm{AFG}_{2}\right.$ ) was significantly reduced compared with the control group in all treatments at the highest concentration tested $(1000 \mu \mathrm{g} / \mathrm{mL})$. No AFs were detected at these concentrations (Table 1) in any case, except for the O. vulgare EO treatment, which achieved reductions of more than $97 \%$ in all toxins.

Table 1. Aflatoxin (AF) concentration $\left(B_{1}, B_{2}, G_{1}\right.$, and $\left.G_{2}\right)$ in Czapek Yeast Autolysate Agar (CYA) plates supplemented with different concentrations $(0,10,100,500$, and $1000 \mu \mathrm{g} / \mathrm{mL})$ of essential oils (EOs) (R. officinalis, T. vulgaris, S. montana, O. virens, O. majoricum, and O. vulgare). Each value is the mean of three replications \pm standard error. Groups with the same letter are not significantly different $(p>0.05)$. ND: non detected.

\begin{tabular}{|c|c|c|c|c|c|}
\hline EOs & $\mu \mathrm{g} / \mathrm{mL}$ & $\mathrm{AFB}_{1}(\mu \mathrm{g} / \mathrm{g}$ agar $)$ & $\begin{array}{c}\mathrm{AFB}_{2}(\mu \mathrm{g} / \mathrm{g} \\
\text { agar })\end{array}$ & $\begin{array}{c}\mathrm{AFG}_{1}(\mu \mathrm{g} / \mathrm{g} \\
\text { agar })\end{array}$ & $\begin{array}{c}\mathrm{AFG}_{2}(\mu \mathrm{g} / \mathrm{g} \\
\text { agar })\end{array}$ \\
\hline \multirow{5}{*}{ R. officinalis } & 0 & $10.754 \pm 0.925^{c}$ & $0.201 \pm 0.021^{\mathrm{c}}$ & $0.485 \pm 0.055^{c}$ & $0.088 \pm 0.014^{b}$ \\
\hline & 10 & $5.205 \pm 1.033^{b c}$ & $0.1 \pm 0.022^{b c}$ & $0.213 \pm 0.045^{b c}$ & $\mathrm{ND}^{\mathrm{a}}$ \\
\hline & 100 & $5.223 \pm 0.171^{a b c}$ & $0.11 \pm 0.006^{b c}$ & $0.216 \pm 0.012^{a b c}$ & $\mathrm{ND}^{\mathrm{a}}$ \\
\hline & 500 & $1.09 \pm 0.152^{a b}$ & $0.017 \pm 0.002^{a b}$ & $0.058 \pm 0.007^{a b}$ & $\mathrm{ND}^{\mathrm{a}}$ \\
\hline & 1000 & $\mathrm{ND}^{\mathrm{a}}$ & $\mathrm{ND}^{\mathrm{a}}$ & $\mathrm{ND}^{\mathrm{a}}$ & $\mathrm{ND}^{\mathrm{a}}$ \\
\hline \multirow{5}{*}{ T. vulgaris } & 0 & $10.754 \pm 0.925^{b}$ & $0.201 \pm 0.021^{b}$ & $0.485 \pm 0.055^{b}$ & $0.088 \pm 0.014^{b}$ \\
\hline & 10 & $7.04 \pm 0.977^{b}$ & $0.122 \pm 0.019^{a b}$ & $0.256 \pm 0.059^{a b}$ & $\mathrm{ND}^{\mathrm{a}}$ \\
\hline & 100 & $5.994 \pm 0.554^{\mathrm{ab}}$ & $0.117 \pm 0.019^{a b}$ & $0.264 \pm 0.069^{a b}$ & $\mathrm{ND}^{\mathrm{a}}$ \\
\hline & 500 & $\mathrm{ND}^{\mathrm{a}}$ & $\mathrm{ND}^{\mathrm{a}}$ & $\mathrm{ND}^{\mathrm{a}}$ & $\mathrm{ND}^{\mathrm{a}}$ \\
\hline & 1000 & $\mathrm{ND}^{\mathrm{a}}$ & $\mathrm{ND}^{\mathrm{a}}$ & $\mathrm{ND}^{\mathrm{a}}$ & $\mathrm{ND}^{\mathrm{a}}$ \\
\hline \multirow{5}{*}{ S. montana } & 0 & $10.754 \pm 0.925^{b}$ & $0.201 \pm 0.021^{b}$ & $0.485 \pm 0.055^{b}$ & $0.088 \pm 0.014^{b}$ \\
\hline & 10 & $8.27 \pm 0.686^{\mathrm{ab}}$ & $0.151 \pm 0.011^{\mathrm{ab}}$ & $0.314 \pm 0.029 \mathrm{ab}$ & $\mathrm{ND}^{\mathrm{a}}$ \\
\hline & 100 & $\mathrm{ND}^{\mathrm{a}}$ & $\mathrm{ND}^{\mathrm{a}}$ & $\mathrm{ND}^{\mathrm{a}}$ & $\mathrm{ND}^{\mathrm{a}}$ \\
\hline & 500 & $\mathrm{ND}^{\mathrm{a}}$ & $\mathrm{ND}^{\mathrm{a}}$ & $\mathrm{ND}^{\mathrm{a}}$ & $\mathrm{ND}^{\mathrm{a}}$ \\
\hline & 1000 & $\mathrm{ND}^{\mathrm{a}}$ & $\mathrm{ND}^{\mathrm{a}}$ & $\mathrm{ND}^{\mathrm{a}}$ & $\mathrm{ND}^{\mathrm{a}}$ \\
\hline \multirow{5}{*}{ O. virens } & 0 & $10.754 \pm 0.925^{b}$ & $0.201 \pm 0.021 \mathrm{bc}$ & $0.485 \pm 0.055^{b}$ & $0.088 \pm 0.014^{b}$ \\
\hline & 10 & $10.52 \pm 1.334^{\mathrm{b}}$ & $0.245 \pm 0.039^{c}$ & $0.508 \pm 0.065^{b}$ & $\mathrm{ND}^{\mathrm{a}}$ \\
\hline & 100 & $0.033 \pm 0.044^{\mathrm{ab}}$ & $0.003 \pm 0^{a b}$ & $0.004 \pm 0.002^{a b}$ & $\mathrm{ND}^{\mathrm{a}}$ \\
\hline & 500 & $\mathrm{ND}^{\mathrm{a}}$ & $\mathrm{ND}^{\mathrm{a}}$ & $\mathrm{ND}^{\mathrm{a}}$ & $\mathrm{ND}^{\mathrm{a}}$ \\
\hline & 1000 & $\mathrm{ND}^{\mathrm{a}}$ & $\mathrm{ND}^{\mathrm{a}}$ & $\mathrm{ND}$ a & $\mathrm{ND}^{\mathrm{a}}$ \\
\hline \multirow{5}{*}{ O. majoricum } & 0 & $10.754 \pm 0.925^{b}$ & $0.201 \pm 0.021^{\mathrm{ab}}$ & $0.485 \pm 0.055^{b}$ & $0.088 \pm 0.014^{b}$ \\
\hline & 10 & $10.939 \pm 0.21^{b}$ & $0.234 \pm 0.008^{b}$ & $0.611 \pm 0.057^{\mathrm{b}}$ & $\mathrm{ND}^{\mathrm{a}}$ \\
\hline & 100 & $7.999 \pm 0.628^{a b}$ & $0.186 \pm 0.022 \mathrm{ab}$ & $0.375 \pm 0.028^{a b}$ & $\mathrm{ND}^{\mathrm{a}}$ \\
\hline & 500 & $0.003 \pm 0^{\mathrm{a}}$ & $\mathrm{ND}^{\mathrm{a}}$ & $\mathrm{ND}^{\mathrm{a}}$ & $\mathrm{ND}^{\mathrm{a}}$ \\
\hline & 1000 & $0.008 \pm 0.008^{a}$ & $\mathrm{ND}^{\mathrm{a}}$ & $\mathrm{ND}^{\mathrm{a}}$ & $\mathrm{ND}^{\mathrm{a}}$ \\
\hline \multirow{5}{*}{ O. vulgare } & 0 & $10.754 \pm 0.925^{c}$ & $0.201 \pm 0.021^{b}$ & $0.485 \pm 0.055^{b}$ & $0.088 \pm 0.014^{b}$ \\
\hline & 10 & $10.143 \pm 0.86^{b c}$ & $0.192 \pm 0.015^{b}$ & $0.475 \pm 0.056^{\mathrm{b}}$ & $\mathrm{ND}^{\mathrm{a}}$ \\
\hline & 100 & $7.867 \pm 0.409 a b c$ & $0.168 \pm 0.015 \mathrm{ab}$ & $0.466 \pm 0.08$ & ND \\
\hline & 500 & $0.738 \pm 0.08 \mathrm{ab}$ & $0.012 \pm 0.002^{\mathrm{a}}$ & $0.043 \pm 0.003$ & ND \\
\hline & 1000 & $0.298 \pm 0.068^{a}$ & $0.004 \pm 0.003^{\mathrm{a}}$ & $0.014 \pm 0.004$ & ND \\
\hline
\end{tabular}

$\mathrm{AFB}_{1}$ production was significantly affected at $500 \mu \mathrm{g} / \mathrm{mL}$, with reductions of nearly $100 \%$ in all of the EOs tested. The same results were obtained when O. virens and S. montana EOs were applied at $100 \mu \mathrm{g} / \mathrm{mL}$.

$\mathrm{AFB}_{2}$ production was also significantly reduced by least $90 \%$ compared with the control plates after treatment with $R$. officinalis, T. vulgaris, O. vulgare, and O. majoricum EOs at $500 \mu \mathrm{g} / \mathrm{mL}$. The most effective treatments, reaching complete inhibition of $\mathrm{AFB}_{2}$ production at $100 \mu \mathrm{g} / \mathrm{mL}$, were O. virens and S. montana EOs. 
Aflatoxin $\mathrm{G}_{1}$ was not detected on S. montana and O. virens at $100 \mu \mathrm{g} / \mathrm{mL}$. The rest of the EOs showed a reduction greater than $80 \%$ at $500 \mu \mathrm{g} / \mathrm{mL}$. In all cases, $\mathrm{AFG}_{2}$ concentration was below the detection limit $(<0.0025 \mu \mathrm{g} / \mathrm{g}$ agar $)$, except in the case of control plates without treatment.

\subsection{Techniques for the Application of Essential Oils to Prevent Fungal Growth and Mycotoxin Production}

The main nanocapsule characteristics of the O. virens and S. montana niosomes can be found in Table 2. According to these data, both encapsulation processes yield high quality niosomes with low aggregation of nanoparticles. The particle size of both samples was approximately $140 \mathrm{~nm}$ with a polydipersity index (PDI) of 0.251 and a $\zeta$-potential of $-14 \mathrm{mV}$.

Table 2. Characterization of $O$. virens and S. montana essential oil particles encapsulated in niosomes.

\begin{tabular}{cccccc}
\hline & \multicolumn{3}{c}{ ZETASICER } & \multicolumn{2}{c}{ NANOSIGHT } \\
\cline { 2 - 6 } & PDI & $\begin{array}{c}\text { Z-AVERAGE } \\
\mathbf{( n m )}\end{array}$ & $\begin{array}{c}\text { POTENCIAL-z, } \\
\mathbf{( m V )}\end{array}$ & Size $(\mathbf{n m})$ & $\begin{array}{c}\text { CONCENTRATION } \\
\mathbf{( P a r t i c l e} / \mathbf{m L})\end{array}$ \\
\hline O. virens & $0.251 \pm 0.019$ & $156.2 \pm 3.9$ & $-14.5 \pm 0.5$ & $142.4 \pm 1.0$ & $(2.96 \pm 0.12) \times 10^{14}$ \\
S. montana & $0.251 \pm 0.011$ & $153.3 \pm 2.8$ & $-14.6 \pm 2.3$ & $140.6 \pm 3.8$ & $(1.86 \pm 0.07) \times 10^{14}$ \\
\hline
\end{tabular}

PDI: polydipersity index.

\subsubsection{Small-Scale Assay}

Satureja montana and O. virens EOs applied by direct contact to artificially inoculated maize grains and incubated at $28{ }^{\circ} \mathrm{C}$ reduced $A$. flavus growth compared with the control group without EOs after seven days of incubation, although no significant differences were observed (Figure 3a). When these EOs were applied in their niosome-encapsulated form and incubated for seven days, colony forming units (CFU) per gram values were slightly increased, although no significant differences were found. When incubation time was extended to 21 days, the opposite effect was observed (Figure $3 b$ ). EOs applied by direct contact seemed to lose their effect over time. However, when these compounds were encapsulated in niosomes, S. montana EO reduced fungal growth by $58 \%$ and, in the case of $O$. virens, this reduction was $32 \%$ with respect to the control group.
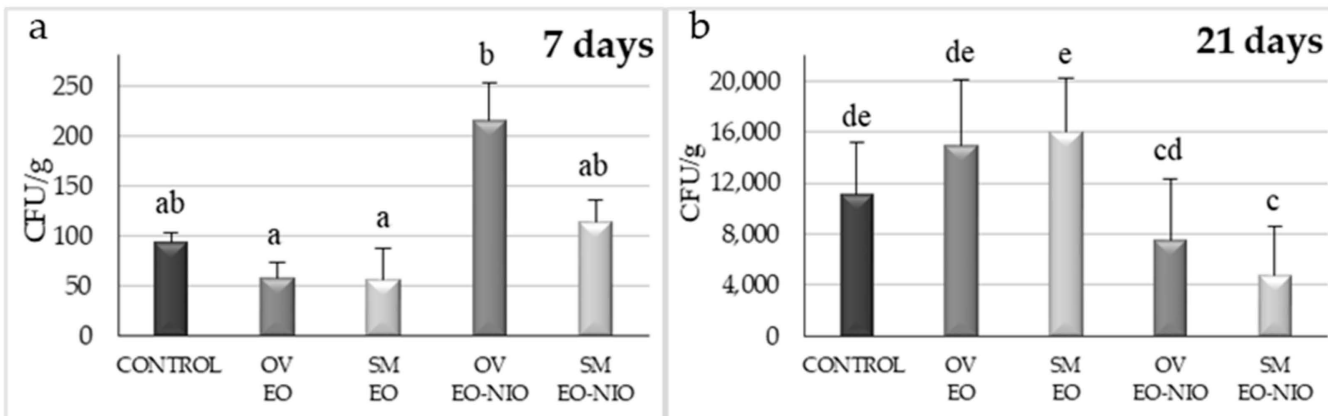

Figure 3. Effect of $S$. montana (SM) and O. virens (OV) by direct contact (essential oil, EO) and immobilized in niosomes (EO-NIO) on corn grains inoculated with A. flavus, incubated for 7 (a) and 21 days (b). Each values is the mean of three replications and the thin vertical bars represent the standard error of the corresponding data. Groups with the same letter are not significantly different $(p>0.05)$. CFU, colony forming units.

$\mathrm{AFB}_{1}$ production was low at the short incubation time (7 days) and very significant for longer periods (21 days) (Figure 4). In the thin layer chromatography (TLC) analysis, the intensity and thickness of the fluorescent band is related to $\mathrm{AFB}_{1}$ concentration. Therefore, in the seven-day long assay, $\mathrm{AFB}_{1}$ concentration was reduced in all cases with respect to control. When plates were incubated over 21 days, a reduction in $\mathrm{AFB}_{1}$ concentration was observed in plates treated directly with $O$. virens 
EO as well as both EO niosome-encapsulated. However, no differences were found after S. montana EO application.

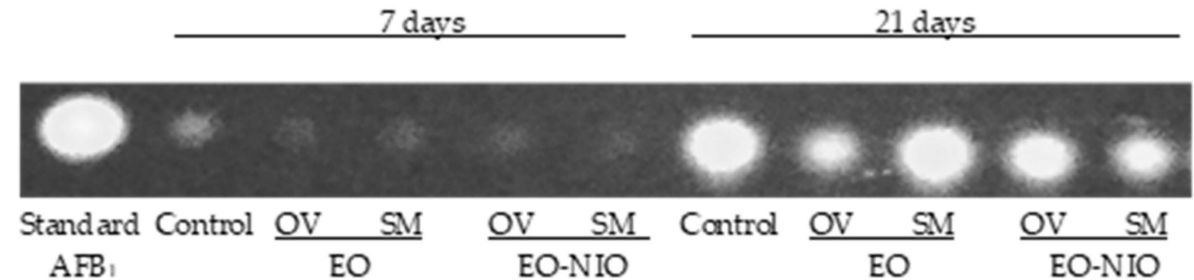

Figure 4. Effect of $S$. montana $(\mathrm{SM})$ and $O$. virens $(\mathrm{OV})$ by direct contact $(\mathrm{EO})$ and encapsulated in niosomes (EO-NIO) on aflatoxin (AF) $\mathrm{B}_{1}$ concentration of corn grains inoculated with A. flavus, incubated for 7 and 21 days. The standard corresponds to the application of purified $\mathrm{AFB}_{1}(0.05 \mathrm{mg} / \mathrm{mL})$.

\subsubsection{Polypropylene Woven Bags Assays}

Figure 5 shows the results in CFU/g of $A$. flavus inoculated corn stored in polypropylene woven bags at all incubation times and after treatment with EOs encapsulated in niosomes.

After 45, 60, and 75 days of incubation, both of the EOs encapsulated in niosomes were able to control fungal growth, with a maximum reduction of up to $79 \%$ and $69 \%$ for S. montana and O. virens EOs, respectively. However, this effect seems to be lost over time and no significant differences with respect to the control group were found after 90 days of incubation.

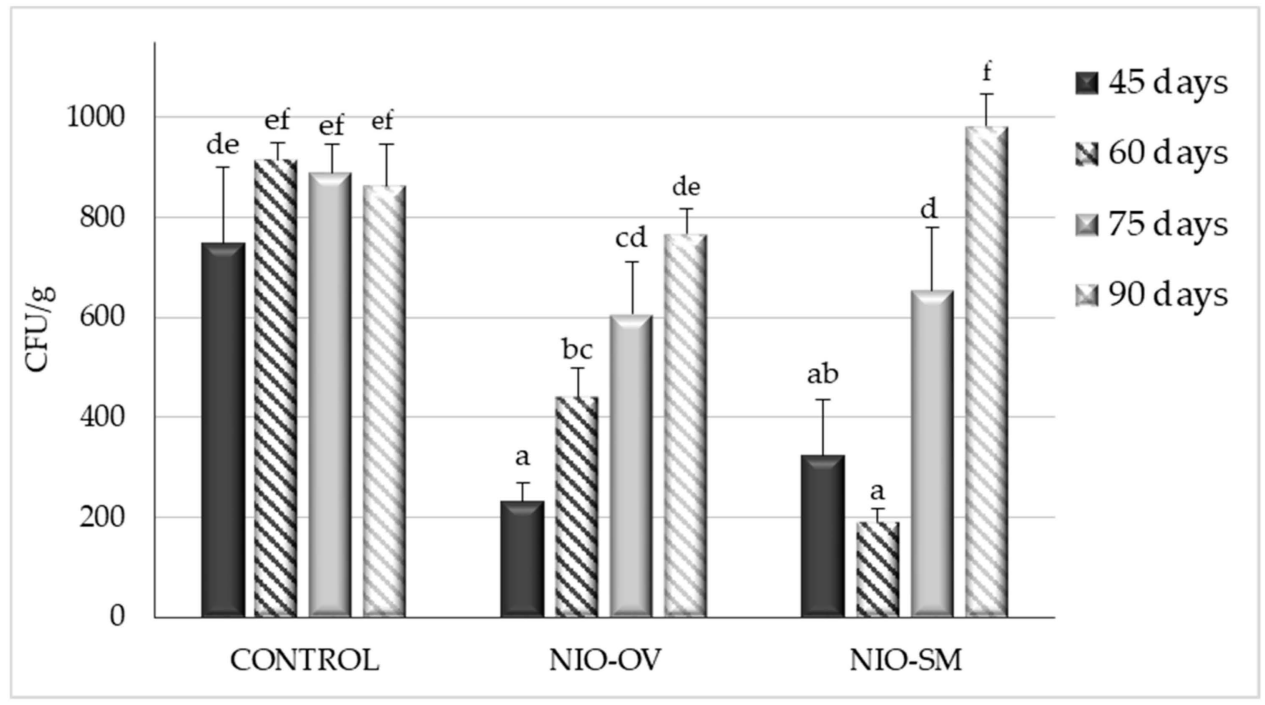

Figure 5. Effect of S. montana (NIO-SM) and O. virens (NIO-OV) EO encapsulated in niosomes on A. flavus growth in corn grains incubated for 45, 60, 75, and 90 days. Each value is the mean of three replications and the thin vertical bars represent the standard error of the corresponding data. Groups with the same letter are not significantly different $(p>0.05)$.

The results regarding $\mathrm{AFB}_{1}$ detected on inoculated control bags or after niosome-encapsulated EO treatments are shown in Figure 6. The band intensity of each treatment was apparently lower with respect to their corresponding control in all cases except for NIO-OV after 90 days of incubation when a slight increase in production was detected. Treatment using niosome-encapsulated S. montana EO was the most effective to control $\mathrm{AFB}_{1}$ production by A. flavus.

Temperature and humidity were recorded during the experiment with ranges of $25-27^{\circ} \mathrm{C}$ and $75-85 \%$, respectively. 


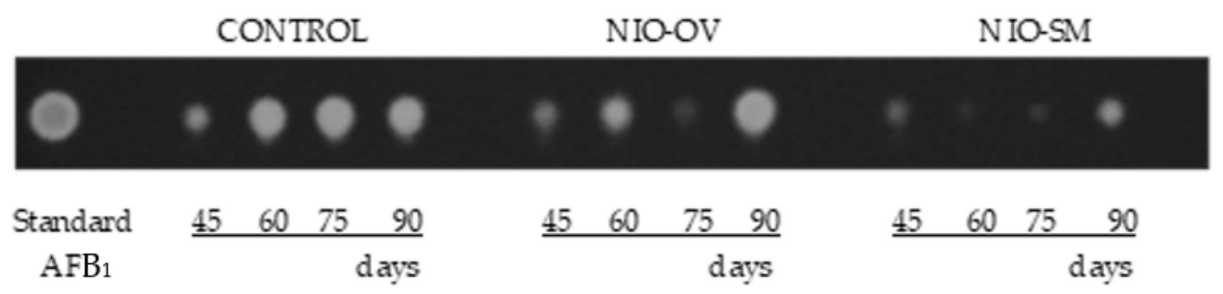

Figure 6. $\mathrm{AFB}_{1}$ detection by thin layer chromatography (TLC) in polypropylene woven bags inoculated with A. flavus after S. montana (NIO-SM) and O. virens (NIO-OV) niosome treatment of corn incubated for $45,60,75$, and 90 days. The intensity and thickness of the fluorescent band are related to the concentration of toxin. The standard corresponds to the application of purified $\mathrm{AFB}_{1}(0.05 \mathrm{mg} / \mathrm{mL})$.

\section{Discussion}

Aflatoxin (AF) presence poses a high risk to food security and most countries have established maximum levels of these contaminants allowed in food products [3]. Appropriate control mechanisms are needed to keep these toxins from entering the food chain. In recent years, essential oils (EOs) have come to be considered as a safe, ecofriendly, renewable, and easily biodegradable option to be used as a food supplement [13]. Moreover, many EOs have been described as potent antifungal compounds that are able to interfere in mycotoxin synthesis [15,25-27]. In this work, we selected EOs extracted from Rosmarinus officinalis, Thymus vulgaris, Satureja montana, Origanum virens, O. majoricum, and O. vulgare to determine if they were able to control Aspergillus flavus growth and if they reduced AF production by this fungus. To some extent, all of the EOs tested modified the fungal growth rate and extended the lag phase at high concentrations. However, at lower doses, the EOs extracted from S. montana and $O$. virens were the most effective at reducing both fungal growth and AF production, and they were selected to perform subsequent studies. Chromatographic characterization of the EOs used in this study were carried out in the Agricultural Research Centre of Albaladejito (data not shown) and the results revealed that S. montana and O. virens EOs are highly rich in carvacrol and thymol, respectively. These compounds have been reported to be able to interact with the cell membrane, disrupt cell permeability, and produce cell death [28]. Pure extracts of both carvacrol and thymol have been reported to inhibit the growth of important mycotoxin-producing species such as $A$. niger, A. flavus, A. ochraceus, and F. graminearum $[29,30]$.

Different authors consider that EO-based formulations could be safe, ecofriendly preservatives to avoid post-harvest losses due to mycotoxin contamination [14]. Therefore, taking into account the potent antifungal properties of EOs, many studies have focused on developing successful application protocols to minimize their drawbacks, which limit their direct use in food products [18] and, therefore, it is essential to protect them to extend their shelf life and activity [19]. The controlled liberation of EOs and their encapsulation in nanoparticles made of different materials are considered a good option $[19,23]$. These technologies attempt to reduce the rapid loss of their active principles. In general, EOs are a complex mix of lipophilic compounds and, therefore, lipid nanoparticle systems such as liposomes are the most appropriate [23,31]. In our study, the small-scale experiments showed that the effectiveness of EOs to control A. flavus growth diminished over time. However, when both EOs were encapsulated in niosomes, a significant reduction in fungal viable counts with respect to the untreated control group were found even after 21 days of incubation. Hence, it seems that the niosome-based nanoparticles were able to reduce the loss of the EOs' active principles and produce a controlled release of their compounds. Similar results were obtained in the larger-scale experiments using maize stored in polypropylene woven bags. This type of storage is very common in African countries because it offers low-cost protection for grain from pests. However, a higher contamination by toxigenic fungi and mycotoxins in the grains has been reported owing to the change in moisture content, which increases the relative humidity inside the bags [32]. Even under the worst conditions for maize storage, both of the EOs encapsulated in niosomes were able to control fungal development, significantly reducing aflatoxin levels, and their effect was extended for up to 75 days. Hence, these promising approaches 
might be useful to prevent AF contamination under more appropriate storage conditions such as PICS (Purdue improved crop storage) bags or directly in silos.

The use of EOs in the agri-food industry is not a safety concern because several studies have ensured that they are safe as food additives and many of them are included in the GRAS list [14]. However, data are scarce regarding the effects that vesicle materials might have on human health and it is essential to carry out ecotoxicity studies to assess the impact of encapsulation matrices [19]. The niosome vesicles used in this work are commercially available and their non-toxic properties have been fully demonstrated. Moreover, they have been approved as a good option for the development of nanoparticles to improve medical therapies, including the controlled delivery of drugs or even vaccine antigens [24].

EO-based formulations need to overcome several tests before their application in food systems, as some active components can interact with food matrix components [14,33]. AFs often occur in maize, one of the most important basic cereal products worldwide for food and feeds [6]. In the present work, S. montana and O. virens EOs encapsulated in niosomes were directly applied to control $A$. flavus growth and its mycotoxigenic potential in artificially contaminated maize as a preliminary step to optimizing their application. EOs' release was effective over time in both small-scale tests and simulated storage conditions and, therefore, no interactions with the components of the maize seemed to occur. It would be interesting to apply this newly developed technology to other food matrices often contaminated with AFs to confirm that this effect could be extrapolated to other products.

\section{Conclusions}

In this work, we proposed a novel niosome-based EO product that was successfully applied in polypropylene woven bags simulating common storage conditions of maize. The involvement of the company Nanovex Biotechnologies S.L. guarantees a correct and standardized encapsulation protocol and the reduction of problems that might arise during product formulation. The presence of encapsulated EOs in the bags significantly reduced $A$. flavus development and the effect was observed until 75 days after inoculation. The effect of this formulation could be easily maximized by applying the products regularly during maize storage, that is, every 45 days. Regularly scheduled application, together with good agricultural practices and the maintenance of adequate storage conditions, may be a sustainable way to avoid the occurrence of aflatoxins in stored maize.

\section{Materials and Methods}

\subsection{Fungal Strains and Essential Oils}

All Aspergillus flavus strains used in this study were able to produce aflatoxins from group $\mathrm{B}\left(\mathrm{AFB}_{1}\right.$ and $\mathrm{AFB}_{2}$ ) and $\mathrm{G}\left(\mathrm{AFG}_{1}\right.$ and $\mathrm{AFG}_{2}$ ) and were isolated from wheat from Morocco (S.44-1) and maize from Spain (A7). The correct identification of these isolates was confirmed using species-specific PCR protocols [34].

The strains were stored as a spore suspension at $-80{ }^{\circ} \mathrm{C}$ in $15 \%$ glycerol (Panreac, Barcelona, Spain) until required. They were subcultured on potato dextrose agar (PDA, Pronadisa, Spain) and incubated at $28{ }^{\circ} \mathrm{C}$ for four days. The spore suspensions were prepared in sterile saline solution $(9 \mathrm{~g} / \mathrm{L}$ sodium chloride) (Merck, Darmstadt, Germany) supplemented by Tween 80 0.5\% (Panreac, Spain). The spore concentration was determined using a Thoma counting chamber (Marienfeld, Lauda-Königshofen, Germany) and adjusted to a final concentration of $10^{2}$ or $10^{6}$ spores $/ \mathrm{mL}$ depending on the assay.

The EOs tested were extracted from rosemary (Rosmarinus officinalis L.), thyme (Thymus vulgaris L.), savory (Satureja montana L.), and three species of oregano (Origanum virens Hoffmanns. \& Link, O. majoricum Camb., and O. vulgare L.). The EOs were provided by The Agricultural Research Centre of Albaladejito (Cuenca, Spain). Each species was processed in batches of 100-150 g of plant aerial parts, following the methodology proposed by the European Pharmacopoeia by hydrodistillation, in a Clevenger-type apparatus for $2 \mathrm{~h}$. These EOs were analyzed in gas chromatograph equipped with a 
flame ionization detector (FID) and capillary column VF- 5 of $60 \mathrm{~mm} \times 0.25 \mathrm{~mm}, 5 \%$ phenyl methyl siloxane. A temperature gradient of 70 to $240{ }^{\circ} \mathrm{C}$ was applied, with an increase of $3{ }^{\circ} \mathrm{C}$ per minute, maintaining the final temperature for $2 \mathrm{~min}$. For the identification of the $\mathrm{EO}$ components, the relative retention times of standards and the corresponding Kovats indices were used. The quantification of the components was performed according to the areas of their chromatographic peaks.

These compounds were filtered (pore size $0.2 \mu \mathrm{m}$ ) (Fisherbrand, Shanghai, China) and stored at $-20{ }^{\circ} \mathrm{C}$ in amber glass vials (Thermo Scientific, Madrid, Spain) until required.

\subsection{Effectiveness of Plant Essential Oils on Fungal Growth and Aflatoxin Production}

The effect of EOs at different concentrations on A. flavus S.44-1 growth and its ability to produce AFs were evaluated on CYA medium ( $45.5 \mathrm{~g} / \mathrm{L}$ of modified Czapek-Dox agar (Pronadisa, Spain), $5 \mathrm{~g} / \mathrm{L}$ of yeast extract (Pronadisa, Spain)). EOs were diluted in polyethylene glycol 400 (PEG (Acros, Geel, Belgium) and added to the medium to obtain final concentrations of $10,100,500$, and $1000 \mu \mathrm{g} / \mathrm{mL}$. The same amount of PEG was included in the control plates instead of EO. CYA plates supplemented with EOs were inoculated with $1.5 \mu \mathrm{L}$ ( $4 \mathrm{~mm}$ of diameter) of a $10^{6}$ spores $/ \mathrm{mL}$ suspension on the center of the plate, and incubated at $28^{\circ} \mathrm{C}$ for five days. All the conditions were tested in triplicate.

Fungal colony diameters were measured daily in two directions at right angles to each other until the medium was fully colonized (five days). Growth parameters were calculated from a linear model obtained by plotting the diameter $(\mathrm{mm})$ against time (day). The parameters determined were $\lambda$, representing the lag phase (days prior to mycelial growth), and $\mu_{\max }$, representing the maximum growth rate $(\mathrm{mm} /$ day), for control plates and each $\mathrm{EO}$ concentration tested.

AFs were extracted from the plates after six days of incubation, as described elsewhere [35]. Three agar plugs were removed from the centre, medium, and outer edge of the colony and toxins were extracted with $1 \mathrm{~mL}$ of methanol (Merck, Spain). Samples were stored at $-20^{\circ} \mathrm{C}$ until analysis. AFs were measured by high performance liquid chromatography (HPLC) using the protocol described below.

\subsection{Effect of Satureja Montana and Origanum Virens Essential Oils Encapsulated in Niosomes on Fungal Growth and Aflatoxin Contamination}

\subsubsection{Procedure for Microencapsulation of Essential Oils}

EOs extracted from S. montana and O. virens were encapsulated in non-ionic surfactant-based lipid vesicles (niosomes). These particles were prepared by Nanovex Biotechnologies S.L. (Oviedo, Spain) starting from $40 \mathrm{~mL}$ of each type of EO. Niosomes were obtained using the thin film hydration (TFH) method with homogenization and sonication to obtain niosomes with a good polydipersity index (PDI) and a particle size between 100 and $200 \mu \mathrm{m}$, with an EO concentration of $12 \mu \mathrm{L} / \mathrm{mL}$.

The characterization of the niosomes was performed with a Zetasizer Nano ZS particle size analyzer (Malvern Panalytical Ltd., Malvern, UK), which uses dynamic light scattering (DLS) to determine particle size, and the M3-PALS technique to calculate the $\zeta$-potential.

A nanoparticle tracking analysis (NTA) was performed using a nano sight particle tracking analyzer (Malvern Panalytical Ltd., Malvern, UK) to determine concentration and size distribution.

5.3.2. Effect of Niosome-Encapsulated Essential Oils on Fungal Growth and Aflatoxin Production on Maize Grains

Previously autoclaved maize grains were inoculated with A. flavus, strain A7. Then, $100 \mathrm{~g}$ of corn was immersed for $2 \mathrm{~h}$ in $100 \mathrm{~mL}$ of spore suspension $10^{4}$ spores/mL to obtain a final concentration of $10^{2}$ spores/g. Subsequently, the effect of niosome-encapsulated EOs was tested in a small-scale test in Petri dishes as well as in polypropylene woven bags simulating real storage conditions. At the beginning of the experiments, grain moisture was measured using a Hygropalm HP23A (Rotronic, Bassersdorf, Switzerland) and water activity was 0.95 in all cases. 


\section{Small-Scale Assays}

Ninety millimeter Petri dishes were filled with crystalized potassium sulphate (Acros, Spain) to maintain $a_{w}$ at 0.97 [36]. A $50 \mathrm{~mm}$ Petri dish containing $7 \mathrm{~g}$ of inoculated maize was placed inside the larger one. Satureja montana and O. virens EOs were applied directly to the grains or encapsulated in niosomes at $500 \mu \mathrm{g} / \mathrm{g}$. Control assays, mock-inoculated with water, were also included. Incubation was performed at $28^{\circ} \mathrm{C}$ and the effect of niosome-encapsulated EOs or those directly applied on maize grains was evaluated at 7 and 21 days.

After the incubation period, a sample of $3.5 \mathrm{~g}$ was taken from each treatment and a viable count was performed using serial decimal dilutions and inoculation on Rose Bengal with Chloramphenicol medium. Plates were incubated in darkness at $28^{\circ} \mathrm{C}$ for two days. The fungal growth of maize grain was expressed as colony forming units per gram of maize (CFU/g).

Afterwards, another sample of $3.5 \mathrm{~g}$ was taken from each treatment, and shaken for $20 \mathrm{~min}$ with $35 \mathrm{~mL}$ of chloroform for $\mathrm{AF}$ extraction. $\mathrm{AFB}_{1}$ was measured by thin layer chromatography (TLC), as described below.

\section{Polypropylene Woven Bag Assays}

One-hundred grams of inoculated maize was placed in small polypropylene woven bags. Subsequently, niosome-encapsulated EOs (S. montana and O. virens) were added at a dose of $500 \mu \mathrm{g} / \mathrm{g}$ and mixed. Bags were incubated at room temperature in darkness for 90 days in independent plastic boxes for each treatment $(40 \times 40 \times 30 \mathrm{~cm})$. Inoculated maize grains without EOs were used as control. Temperature and relative humidity were registered using a data logger El-USB-1 (Easylog; LASCAR electronic, Salisbury, UK) every $8 \mathrm{~h}$ until the end of the assay.

After the incubation period, the bags were cut open and the maize was diluted in $900 \mathrm{~mL}$ of sterile saline solution $(9 \mathrm{~g} / \mathrm{L})$ containing $0.05 \%$ Tween 80 . The mixes were incubated in an orbital shaker (140 rpm) at $4{ }^{\circ} \mathrm{C}$ for $60 \mathrm{~min}$ to release spores. Then, serial decimal dilutions and culture in Rose Bengal with Chloramphenicol were used to estimate fungal growth as CFU per gram of maize.

A sample of $14 \mathrm{~g}$ of corn was taken from each beaker, and shaken for 20 min with $35 \mathrm{~mL}$ of chloroform for $\mathrm{AFB}_{1}$ extraction and subsequent evaluation by TLC, as described below.

\subsection{Detection of Mycotoxins}

\subsubsection{Detection of Mycotoxins by High Performance Liquid Chromatography (HPLC)}

After $\mathrm{AFB}_{1}$ extraction with methanol, mycotoxin measurements were performed in the "Laboratorio Arbitral Agroalimentario" (Madrid, Spain) following its standardized protocols. AF was measured by HPLC on a reverse phase $C_{18}$ column (Inertsil ODS3; $5 \mu \mathrm{m}, 4.6 \mathrm{~mm} \times 250 \mathrm{~mm}$; GL Sciences, Tokio, Japan) at $40{ }^{\circ} \mathrm{C}$ in a Waters chromatograph 515 HPLC coupled with a fluorescence detector 474 (Waters, Milford, MA, USA) at excitation and emission wavelengths of 362 and $435 \mathrm{~nm}$, respectively. The mobile phase contained water, methanol, and acetonitrile (60:20:20), and the flow rate was $1 \mathrm{~mL} / \mathrm{min}$. AF was eluted and quantified by comparison with a calibration curve generated from AF standards $\left(\right.$ OEKANAL ${ }^{\circledR}$, Sigma-Aldrich, Steinheim, Germany). The detection limit of the technique was $2.5 \mathrm{ng} / \mathrm{g}$.

\subsubsection{Detection of Mycotoxins by Thin Layer Chromatography}

After $\mathrm{AFB}_{1}$ extraction with chloroform, samples were filtered using $0.45 \mu \mathrm{m}$ syringe filters (Fisherbrand, Spain) and an aliquot of $1 \mathrm{~mL}$ was evaporated in a vacuum concentrator, Eppendorf ${ }^{\mathrm{TM}}$ Concentrator Plus with Pump and GB Plug (Fisher Scientific, Madrid, Spain).

Silica gel 60 chromatography plates (Merck, Germany) were used, and $\mathrm{AFB}_{1}$ presence was determined according to the protocols described elsewhere $[37,38]$. 
Samples and AF standards were re-suspended with $500 \mu \mathrm{L}$ toluene/acetonitrile (95:5) (Panreac, Spain). Then, $10 \mu \mathrm{L}$ of each sample was spotted on the plate. Toluene/acetone/acetonitrile (1:1:1 (LabKem, Barcelona, Spain)) was used as a mobile phase. Toxins were visualized under ultraviolet light (Spectronics, Westbury, NY, USA).

\subsection{Statistical Analysis}

Statistical analysis was performed on the effect of EOs encapsulated in niosomes with StatsGraphics Centurion XVII V.17.2.04 program (Statpoint Technologies Inc., Warrenton, VA, USA). The Shapiro-Wilk and Levene tests were used to check normality and homoscedasticity, respectively. Data were analysed using analysis of variance (ANOVA).

When data did not meet normality and homoscedasticity criteria, a non-parametric Kruskall-Wallis test was performed. These analyses were performed using the software InfoStat/E 2011 (FCA, Córdoba, Argentina). This was necessary in the case of the fungal growth and aflatoxin production variables indicated in Section 5.2 of Material and Methods.

In all cases, the significance level was set at $p<0.05$.

Author Contributions: All authors conceived the experimental design. M.G.-D., J.G.-S., and B.P. helped with laboratory analysis. M.G.-D. and J.G.-S. performed statistical analysis and wrote the original draft. B.P. and C.V. reviewed and edited the manuscript. All authors read and approved the final version of the document.

Funding: This research was supported by the Spanish Ministry of Science and Innovation, grant number AGL 2014-53928-C2-2-R, and Marta García-Díaz was funded through an FPI fellowship by the Spanish Ministry of Science and Innovation (BES-2015-074533).

Acknowledgments: The authors would like to thank the Agricultural Research Centre of Albaladejito for supplying the purified essential oils, as well as "Laboratorio Arbitral Agroalimentario" for the measurements of mycotoxins using HPLC. Nanovex Biotechnologies was our partner in the process of encapsulating essential oils.

Conflicts of Interest: The authors declare no conflict of interest.

\section{References}

1. Kensler, T.W.; Roebuck, B.D.; Wogan, G.N.; Groopma, J.D. Aflatoxin: A 50-year odyssey of mechanistic and translational toxicology. Toxicol. Sci. 2011, 120, S25-S48. [CrossRef] [PubMed]

2. Alshannaq, A.; Yu, J.H. Occurrence, toxicity, and analysis of major mycotoxins in food. Int. J. Environ. Res. Public Health 2017, 14, 632. [CrossRef] [PubMed]

3. Wu, F.; Stacy, S.L.; Kensler, T.W. Global risk assessment of aflatoxins in maize and peanuts: Are regulatory standards adequately protective? Toxicol. Sci. 2013, 135, 251-259. [CrossRef] [PubMed]

4. Gil-Serna, J.; Vázquez, C.; Patiño, B. Mycotoxins/Toxicology. In Encyclopedia of Food Microbiology; Academic Press: Cambridge, MA, USA, 2014.

5. Food and Agriculture Organization of the United Nations, Statistic Division. Available online: http://www.fao. org/faostat/en/\#data/QC (accessed on 18 September 2019).

6. Battilani, P.; Toscano, P.; van der Fels-Klerx, H.J.; Jeggieri, M.C.; Brera, C.; Rortais, A.; Goumperis, T.; Robinson, T. Aflatoxin $\mathrm{B}_{1}$ contamination in maize in Europe increases due to climate change. Sci. Rep. 2016, 6, 24328. [CrossRef] [PubMed]

7. European Commission. Regulation $N^{\circ} 165 / 2010$ amending Regulation (EC) No 1881/2006 setting maximum levels for certain contaminants in foodstuffs as regards aflatoxins. Off. J. Eur. Union 2010, 50, 8-12.

8. Hussein, H.S.; Brasel, J.M. Toxicity, metabolism, and impact of mycotoxins on humans and animals. Toxicology 2001, 167, 101-134. [CrossRef]

9. Chulze, S. Strategies to reduce mycotoxin levels in maize during storage: A review. Food Addit. Contam. 2010, 27, 651-657. [CrossRef]

10. Lagogianni, C.S.; Tsisigiannis, D.I. Effective chemical management for prevention of aflatoxins in maize. Phytopathol. Mediterr. 2018, 57, 186-197.

11. Ji, C.; Fan, J.; Zhao, L. Review on biological degradation of mycotoxins. Anim. Nutr. 2016, 2, 127-133. [CrossRef] 
12. Da Cruz Cabral, L.; Pinto, V.F.; Patriarca, A. Application of plant derived compounds to control fungal spoilage and mycotoxin production in foods. Int. J. Food Microbiol. 2013, 166, 1-14. [CrossRef]

13. Pandey, A.K.; Kumar, P.; Singh, P.; Tripathi, N.N.; Bajpai, V.K. Essential oils: Sources of antimicrobials and food preservatives. Front. Microbiol. 2017, 7, 2161. [CrossRef] [PubMed]

14. Kumar-Dwivedy, A.; Kumar, M.; Updhyay, N.; Prakash, B.; Kishore-Dubey, N. Plant essential oils against food borne fungi and mycotoxins. Curr. Opin. Food Sci. 2016, 11, 16-21. [CrossRef]

15. Da Silva, N.; Polis, L.; Faggion, J.; Yumie, C.; Galerani, S.A.; Grespan, R.; Botiao, S.; Augusto, C.; Abreu, B.A.; Machinski, M. Antifungal activity and inhibition of fumonisin production by Rosmarinus officinalis L. essential oil in Fusarium verticillioides (Sacc.) Nirenberg. Food Chem. 2015, 166, 330-336. [CrossRef] [PubMed]

16. Esper, R.H.; Gonçalez, E.; Marques, M.O.M.; Felicio, R.C.; Felicio, J.D. Potential of essential oils for protection of grains contaminated by aflatoxin produced by Aspergillus flavus. Front. Microbiol. 2014, 5, 269. [CrossRef] [PubMed]

17. Kedia, A.; Kumar-Dwivedy, A.; Kumar-Jha, D.; Dubey, N.K. Efficacy of Mentha spicata essential oil in suppression of Aspergillus flavus and aflatoxin contamination in chickpea with particular emphasis to mode of antifungal action. Protoplasma 2016, 253, 647-653. [CrossRef]

18. Ribeiro-Santos, R.; Andrade, M.; Sanches-Silva, A. Application of encapsulated essential oils as antimicrobial agents in food packaging. Food Sci. 2017, 14, 78-84. [CrossRef]

19. Mäes, C.; Bouquillon, S.; Fauconnier, M.L. Encapsulation of essential oils for the development of biosourced pesticides with controlled release: A review. Molecules 2019, 24, 2539. [CrossRef]

20. Donsí, F.; Annunziata, M.; Sessa, M.; Ferrari, G. Nanoencapsulation of essential oils to enhance their antimicrobial activity in foods. LWT Food Sci. Technol. 2011, 44, 1908-1914. [CrossRef]

21. Nesci, A.; Passone, M.A.; Barra, P.; Girardi, N.; García, D.; Etcheverry, M. Prevention of aflatoxin contamination in stored grains using chemical strategies. Curr. Opin. Food Sci. 2016, 11, 56-60. [CrossRef]

22. Da Silva, P.T.; Fries, L.L.M.; de Menezes, C.R.; Holken, A.T.; Schwan, C.L.; Wigmann, E.F.; Bastos, J.D.O.; da Silva, C.D.B. Microencapsulation: Concepts, mechanisms, methods and some applications in food technology. Cienc. Rural 2014, 44, 1304-1311. [CrossRef]

23. Prakash, B.; Kujur, A.; Yadav, A.; Kumar, A.; Singh, P.P.; Dubey, N.K. Nanoencapsulation: An efficient technology to boost the antimicrobial potential of plant essential oils in food system. Food Control 2018, 89, 1-11. [CrossRef]

24. Amoabediny, G.; Haghiralsadat, F.; Naderinezhad, S.; Helder, M.N.; Kharanaghi, E.A.; Arough, J.M.; Zandieh-Doulabi, B. Overview of preparation methods of polymeric and lipid-based (niosome, solid lipid, liposome) nanoparticles: A comprehensive review. Int. J. Polym. Mater. Polym. Biomater. 2018, 67, 383-400. [CrossRef]

25. Císarová, M.; Tancinová, D.; Medo, J.; Kacaniová, M. The in vitro effect of selected essential oils on the growth and mycotoxin production of Aspergillus species. J. Environ. Sci. Health Part B 2016, 51, 668-674. [CrossRef] [PubMed]

26. Perczak, A.; Gwiazdowska, D.; Marchwinska, D.; Jus, K.; Gwiazdowski, R.; Waskiewicz, A. Antifungal activity of selected essential oils against Fusarium culmorum and F. graminearum and their secondary metabolites in wheat seeds. Arch. Microbiol. 2019, 201, 1085-1097. [CrossRef]

27. Wang, L.; Jiang, N.; Wang, D.; Wang, M. Effects of essential oil citral on the growth, mycotoxin biosynthesis and transcriptomic profile of Alternaria alternate. Toxins 2019, 11, 553. [CrossRef]

28. Prakash, B.; Kedia, A.; Mishra, P.K.; Dubey, N.K. Plant essential oils as food preservatives to control moulds, mycotoxin contamination and oxidative deterioration of agri-food commodities-Potentials and challenges. Food Control 2015, 47, 381-391. [CrossRef]

29. Abbaszadeh, S.; Sharifzadeh, A.; Shokri, H.; Khosravi, A.R.; Abbaszadeh, A. Antifungal efficacy of thymol, carvacrol, eugenol and menthol as alternative agents to control the growth of food-relevant fungi. J. Mycol. Med. 2014, 24, 51-56. [CrossRef]

30. Gao, T.; Zhou, H.; Zhow, W.; Hu, L.; Chen, J.; Shi, Z. The fungicidal activity of thymol against Fusarium graminearum via inducing lipid peroxidation and disrupting ergosterol biosynthesis. Molecules 2016, 21, 770. [CrossRef]

31. Zeisig, R.; Cammerer, B. Liposomes in the food industry. In Nano-and Microencapsulation for Foods; Vilstrup, P., Ed.; Leatherhead: London, UK, 2001; pp. 101-109. 
32. Maina, A.W.; Wagacha, J.M.; Mwaura, F.B.; Muthomi, J.W.; Woloshuk, C.P. Postharvest practices of maize farmers in Kaiti district, Kenya and the impact of hermetic storage on populations of Aspergillus spp. and aflatoxin contamination. J. Food Res. 2016, 5, 53-66. [CrossRef]

33. Perricone, M.; Arace, E.; Corbo, M.R.; Sinigaglia, M.; Bevilacqua, A. Bioactivity of essential oils: A review on their interaction with food components. Front. Microbiol. 2015, 6, 76. [CrossRef]

34. González-Salgado, N.; González-Jaén, M.T.; Vázquez, C.; Patiño, B. Highly sensitive PCR-based detection method specific for Aspergillus flavus in wheat flour. Food Addit. Contam. 2008, 25, 758-764. [CrossRef] [PubMed]

35. Bragulat, M.R.; Abarca, M.L.; Cabañes, F.J. An easy screening method for fungi producing ochratoxin A in pure culture. Int. J. Food Microbiol. 2001, 71, 139-144. [CrossRef]

36. Bernáldez-Rey, M.V. Desarrollo de Métodos de RT-PCR en Tiempo Real Para la Cuantificación de Mohos Toxigénicos Viables en Alimentos. Ph.D. Thesis, University of Extremadura, Badajoz, Spain, 2016.

37. Scott, P.M.; Lawrence, J.W.; van Walbeek, W. Detection of mycotoxins by thin-layer chromatography: Application to screening of fungal extracts. Appl. Microbiol. 1970, 20, 839-842. [PubMed]

38. Gimeno, A.; Martins, M.L. Rapid thin layer chromatography determination of patulin, citrinin, and aflatoxin in apples and pears, and their juices and jams. J. Assoc. Off. Anal. Chem. 1983, 66, 85-91.

(C) 2019 by the authors. Licensee MDPI, Basel, Switzerland. This article is an open access article distributed under the terms and conditions of the Creative Commons Attribution (CC BY) license (http://creativecommons.org/licenses/by/4.0/). 